\title{
Changing Student Perception of an Online Integrated Structured Clinical Examination During the COVID- 19 Pandemic - Authors Reply [Response to Letter]
}

\author{
Sashiananthan \\ Ganesananthan (D) ${ }^{1-3}$ \\ Chunhei $\mathrm{Li}^{4}$ \\ Timothy Woo ${ }^{5}$ \\ Anastasia Donnir ${ }^{6}$ \\ Anthony Anthony ${ }^{7}$ \\ Ankur Khajuria ${ }^{8,9}$ \\ 'West Middlesex University Hospital, \\ Chelsea and Westminster NHS \\ Foundation Trust, London, UK; \\ ${ }^{2}$ Department of Metabolism, Digestion \\ and Reproduction, Faculty of Medicine, \\ Imperial College London, London, UK; \\ ${ }^{3}$ National Heart and Lung Institute, \\ Imperial College London, London, UK; \\ ${ }^{4}$ St George's Hospital, St George's \\ University Hospital NHS Foundation \\ Trust, London, UK; ${ }^{5}$ King's College \\ Hospital, King's College Hospital NHS \\ Foundation Trust, London, UK; ${ }^{6}$ Walsall \\ Manor Hospital, Walsall Healthcare NHS \\ Trust, Walsall, UK; ${ }^{7}$ University Hospital \\ Wales, NHS Wales, Cardiff, UK; \\ ${ }^{8}$ Honorary Clinical Research Fellow, \\ Department of Surgery and Cancer, \\ Imperial College London, London, UK; \\ ${ }^{9}$ Kellogg College, University of Oxford, \\ Oxford, UK
}

\section{Dear editor}

We would like to thank $\mathrm{Chu}$ and Hale ${ }^{1}$ for their comments regarding our recent paper published in the journal. ${ }^{2}$ As an insight to how our summative ISCEs ran at our institution, we eventually executed these in-person. This consisted of two separate days to accommodate all our students. Each student only participated in one of these days which consisted of 8 stations assessing different competencies. The exact stations varied during each day and lasted 15-minutes each. Each of these stations consisted of an examiner and simulated (student actors/paid actors) patients. This was in place of previous ISCEs which consisted of four stations for three days for each student with real patients. The safety of these assessments was also given utmost priority. Students had to wear full personal protective equipment and change between each station. Collectively, these modifications also allowed our institution to run our summative examinations in a timely and safe manner.

We agree with Chu and Hale that cheating is an important issue to address with summative examinations especially online examinations, although this is not a new phenomenon. To circumvent this in multiple choice examinations, many universities have employed open book examinations. ${ }^{3,4}$ However, for clinical examinations, due to the subjective nature and vast content that can be potentially tested, it is potentially not as easy to cheat. Furthermore, post graduate examinations such as the MRCP and MRCS have employed the need for candidates to disclose contents of their room and walls before sitting the examination. ${ }^{5}$ This could also be employed in these online clinical examinations. However, we appreciate that assessing ease/risk of cheating would have provided a useful assessment for our study. In terms of word cloud analysis (supplementary 3.1-3.2) for this concept of cheating or unfair practice (We employed the open-ended question pre and post ISCE questionnaire - is there anything else you are worried about if Medical School Finals were done on an ONLINE format?), concerns on cheating or unfair practice was mentioned by $2 / 84$ (3.1\%) participants in the pre questionnaire and $1 /$ $64(1.6 \%)$ in the post-questionnaire.

With regards to polling students' perceptions regarding online vs in-person OSCEs, these results are presented in the main paper showing that students were more worried and less confident performing ISCEs online vs in-person. However, we have no data on the change of this following our mock or considering alternatives for in-person assessments. We agree that it might be interesting to assess these results post-online mock ISCE.
Correspondence: Sashiananthan Ganesananthan

National Heart and Lung Institute, Imperial College London, London, UK Email Sashiananthan.Ganesananthan@nhs. net 
In conclusion, we agree with $\mathrm{Chu}$ and $\mathrm{Hale}^{1}$ that peer-led mock examinations help improve confidence in online ISCEs and provide valuable feedback for students. We have always believed that online assessments should not replace but rather supplement inperson alternatives given the current climate in medical education. An up-to-date nationwide assessment of students' views with regards to these online assessments given recent exposure to in-person alternative could be warranted.

\section{Disclosure}

No conflicts of interest declared in this communication.

\section{References}

1. Chu S, Hale S. A response to "changing student perception of an online integrated structured clinical examination during the COVID19 pandemic" [Letter]. Adv Med Educ Pract. 2021;12:1019-1020. doi:10.2147/AMEP.S336169

2. Ganesananthan S, Li C, Donnir A, et al. Changing student perception of an online integrated structured clinical examination during the COVID-19 pandemic. Adv Med Educ Pract. 2021;12:887-894. doi:10.2147/AMEP.S325364

3. Sam AH, Reid MD, Amin A. High-stakes, remote-access, open-book examinations. Med Educ. 2020;54(8):767-768. doi:10.1111/ medu. 14247

4. Birch E, de Wolf M. A novel approach to medical school examinations during the COVID-19 pandemic. Med Educ. 2020;25(1):1785680. doi:10.1080/10872981.2020.1785680

5. MRCPUK. Part 1 UK online exam; 2021. Available from: https://www. mrcpuk.org/part-1-uk-online-exam. Accessed September 24, 2021.

Dove Medical Press encourages responsible, free and frank academic debate. The content of the Advances in Medical Education and Practice 'letters to the editor' section does not necessarily represent the views of Dove Medical Press, its officers, agents, employees, related entities or the Advances in Medical Education and Practice editors. While all reasonable steps have been taken to confirm the content of each letter, Dove Medical Press accepts no liability in respect of the content of any letter, nor is it responsible for the content and accuracy of any letter to the editor.

\section{Publish your work in this journal}

Advances in Medical Education and Practice is an international, peerreviewed, open access journal that aims to present and publish research on Medical Education covering medical, dental, nursing and allied health care professional education. The journal covers undergraduate education, postgraduate training and continuing medical education including emerging trends and innovative models linking education, research, and health care services. The manuscript management system is completely online and includes a very quick and fair peer-review system. Visit http://www.dovepress.com/testimonials.php to read real quotes from published authors. 